\title{
A Research on Prediction about Air passenger Traffic in the Capital Airport Area
}

\author{
Xiang Chao ${ }^{1, a}$, Xifu Wang ${ }^{2, b}$ \\ ${ }^{1}$ School of Traffic and Transportation, Beijing Jiaotong UniVersity, Beijing, 100044, China \\ ${ }^{2}$ School of Traffic and Transportation, Beijing Jiaotong UniVersity, Beijing, 100044, China \\ aemail:14120815@bjtu.edu.cn bemail: xfwang1@bjtu.edu.cn
}

\begin{abstract}
Keywords: Regression analysis; air passenger traffic; Forecast Model
Abstract: With the continuous development of China's economic level, the amount of air traffic has improved a lot. More and more airports are constructed or expanded in China. in order to avoid the waste of resources caused by too large-scale planning, prediction for air traffic has occupied a more and more important position. Based on the detailed analysis of factors affecting the air passenger traffic, combined with the use of SPSS13.0 software, we try to find out how these factors affect air traffic and how they affect each other. Some methods like trend extrapolation and linear regression analysis are also used in this paper. Considering all these factors together and using these methods mentioned above to get a final predict result.
\end{abstract}

\section{introduction}

Beijing Capital international Airport as our representative airport has maintained a rapid growth trend. Under the new development circumstance, Beijing Capital international Airport is facing a series of issues such as alteration and expansion constructions of the terminals; the planning and construction of the Second Capital Airport. In this context, air passenger traffic forecast is particularly important to the BCIA, which will involves some critical issues like alteration and expansion constructions and future positioning of Second Capital Airport.

The target year for the prediction is 2018, when the construction of the Second Capital Airport will be finished and put into use. it should be noted that the final values of prediction include not only the air passenger traffic in BCIA but also the air passenger traffic possible existed in Second Capital Airport. So, the Capital Airport mentioned in this paper includes both BCIA and Second Capital Airport.

\section{Example of application}

The accurate prediction about the air passenger traffic is based on the correct analysis of the impact factors in the air passenger traffic. Only when these factors are analyzed correctly and put these factors into the real prediction can we calculate a precise result about prediction. There are many factors impacting air passenger traffic, in this paper, some mainly factors will be listed and analyzed to find out the relationship between air passenger traffic and impact factors.

The impact factors are listed as follows: Tourism foreign exchange earnings; Regional economic development level, That is the total amount of area GDP; Area per capita disposable incomes level; Total resident population in airport area; the development of other transportation modes and the 
surrounding the airport in airport area and theirs impacts on the air passenger traffic.

The data of the above factors as well as the air passenger traffic are shown in Table i.

Table i. Lists of factors

\begin{tabular}{cccccc}
\hline Year & $\begin{array}{c}\text { Tourism } \\
\text { earnings }\end{array}$ & GDP & $\begin{array}{c}\text { disposable } \\
\text { incomes }\end{array}$ & population & $\begin{array}{c}\text { air passenger } \\
\text { traffic }\end{array}$ \\
\hline 1990 & 65706.00 & 500.80 & 1787.00 & 1086.00 & 4820811.00 \\
1991 & 85001.00 & 598.90 & 2040.00 & 1094.00 & 6309538.00 \\
1992 & 107286.00 & 709.10 & 2363.00 & 1102.00 & 8699677.00 \\
1993 & 124128.00 & 886.20 & 3296.00 & 1112.00 & 10552090.00 \\
1994 & 200904.00 & 1145.30 & 4731.00 & 1125.00 & 11852273.00 \\
1995 & 218200.00 & 1507.70 & 5868.00 & 1251.10 & 15267422.00 \\
1996 & 225200.00 & 1789.20 & 6885.00 & 1259.40 & 16612578.00 \\
1997 & 224800.00 & 2077.10 & 7813.00 & 1240.00 & 17101857.00 \\
1998 & 238400.00 & 2377.20 & 8472.00 & 1245.60 & 17516960.00 \\
1999 & 249600.00 & 2678.80 & 9183.00 & 1257.20 & 18348696.00 \\
2000 & 276800.00 & 3161.70 & 10349.00 & 1363.60 & 21870700.00 \\
2001 & 295000.00 & 3708.00 & 11577.00 & 1385.10 & 24442209.00 \\
2002 & 311000.00 & 4315.00 & 12463.00 & 1423.20 & 27363430.00 \\
2003 & 190000.00 & 5007.20 & 13882.00 & 1456.40 & 24283818.00 \\
2004 & 317000.00 & 6060.00 & 15637.00 & 1492.70 & 34883190.00 \\
2005 & 362000.00 & 6969.52 & 17653.00 & 1538.00 & 41031321.00 \\
2006 & 402600.00 & 8117.78 & 19978.00 & 1601.00 & 49049343.00 \\
2007 & 458000.00 & 9846.81 & 21989.00 & 1676.00 & 54365162.00 \\
2008 & 446000.00 & 11115.00 & 24725.00 & 1771.00 & 57295174.00 \\
2009 & 436000.00 & 12153.03 & 26738.00 & 1860.00 & 66982690.00 \\
2010 & 504400.00 & 14113.58 & 29073.00 & 1961.90 & 76088588.00 \\
2011 & 541600.00 & 16251.93 & 32903.00 & 2018.60 & 77403668.00 \\
2012 & 515061.00 & 17879.40 & 36469.00 & 2069.30 & 81908740.00 \\
2013 & 479522.00 & 19500.60 & 40321.00 & 2114.80 & 83712309.00 \\
\hline & & & & &
\end{tabular}

Using regression analysis to check whether these impact factors such as Tourism foreign exchange earnings; Regional economic development level; Area per capita disposable incomes level; Total resident population in airport area have influences on air passenger traffic or the influences are significant or not. There will be following steps to establish the linear regression equation:

1. Define the air passenger traffic as variable $Y$, tourism foreign exchange earnings as $X_{1}$, regional economic development level as $X_{2}$, area per capita disposable income level as $X_{3}$, total resident population in airport area as $X_{4}$. 
2. Multicollinearity test: to check whether there is multicollinearity between $X_{1}, X_{2}, X_{3}, X_{4}$, a principal component analysis will be done using SPSS13. The analysis results are listed in Table ii and Table iii below. As we can see from the output tables below, component 1 holds $97 \%$ of the initial Eigenvalues, which means this component includes all the basic information and selected from variables. So only 1 component is generated, which means the equation is transformed from multiple linear regression to simple linear regression. Mark the newly-generated component with $W$.

Table ii. Total Variance Explained

\begin{tabular}{|c|c|c|c|c|c|c|}
\hline \multirow{2}{*}{ Component } & \multicolumn{3}{|c|}{ in itial Eigenvalues } & \multicolumn{3}{c|}{ Extraction Sums of Squared Loadings } \\
\cline { 2 - 6 } & Total & \% of Variance & Cumulative \% & Total & \% of Variance & Cumulative \% \\
\hline 1 & 3.891 & 97.272 & 97.272 & 3.891 & 97.272 & 97.272 \\
2 & .098 & 2.451 & 99.722 & & & \\
3 & .007 & .187 & 99.910 & & & \\
4 & .004 & .090 & 100.000 & & & \\
\hline
\end{tabular}

Extraction Method: Principal Component Analysis.

Table iii. Component Matrix (a)

\begin{tabular}{|c|c|}
\hline & Component \\
\hline & 1 \\
\hline Tourism & .964 \\
GDP & .989 \\
incomes & .996 \\
population & .996 \\
\hline
\end{tabular}

3. Put the newly-generated component into the regression model. The results of variance analysis for regression equation show that the value of $\mathrm{F}$ is 2166 and the value of significant is about to 0 . As is shown in Table $\mathrm{iV}$, the coefficient is $35323426.833,26104826.373$. So the regression equation is shown as follows:

$$
Y=26104826.373 W+35323426.833
$$

Table iV. Coefficient

\begin{tabular}{|c|c|c|c|c|c|}
\hline \multirow[t]{2}{*}{ Model } & & \multicolumn{2}{|c|}{ Unstandardized Coefficients } & \multirow{2}{*}{$\begin{array}{c}\text { Standardized } \\
\text { Coefficients } \\
\text { Beta }\end{array}$} & \multirow[b]{2}{*}{ Sig. } \\
\hline & & $\mathrm{B}$ & Std. Error & & \\
\hline 1 & $\begin{array}{l}\text { (Constant) } \\
\text { REGR factor score } 1 \\
\text { for analysis } 1\end{array}$ & $\begin{array}{l}35323426.833 \\
26104826.373\end{array}$ & $\begin{array}{l}549044.667 \\
560853.430\end{array}$ & $\begin{array}{r}3.891 \\
.995\end{array}$ & $\begin{array}{l}.000 \\
.000\end{array}$ \\
\hline
\end{tabular}

4. Using the trend extrapolation to find out trend extrapolation equation: 


$$
W=0.0049 w^{2}+0.0162 w-1.1931
$$

The prediction value of the component in 2018 will be 3.3976. Putting the value into formula (1), the prediction value of the air passenger traffic $Y$ :

$$
\begin{aligned}
& Y=26104826.373 W+35323426.833 \\
& =26104826.373 \times 3.3976+35323426.833 \\
& =124017184.91791
\end{aligned}
$$

So, the prediction value of the air passenger traffic will be about 120 millions in Beijing region.

\section{Conclusions}

Through the analysis of factors affecting the air passenger traffic in BCiA and the Second Capital Airport, we can find out some conclusions:

1. Taking the advantage of the special strategic position and the superior resource allocation, with the rapid development of economic level in our country, BCiA and the Second Capital Airport will usher in a new round of air passenger traffic growth.

2. The prediction value of the air passenger traffic will be about 120 millions in Beijing region. in order to meet the air passenger traffic, BCiA has already finished the construction of newly-built Terminal 3 and put in into use in 2008 and expanded the passenger capacities in T1、T2. After the renovation, the passenger capacity of the 3 terminal buildings is about 80 millions, which cannot match the pace of The rapid growth of air passenger traffic in Beijing region apparently. The construction schedule of the Second Capital Airport has already existed and is expected to up and running by 2018, the Second Capital Airport will play an important role in shunting passenger then. The final goal of the Second Capital Airport is to shunt half of the air passenger traffic in Beijing region.

\section{References}

[1]. Guoyan Li. Research on the key problems of prediction of air traffic of ciVil airport construction project [J]. Nanjing UniVersity of Aeronautics \& Astronautics, 2005.

[2]. Xu Zhang. Research on the development of high speed railway and ciVil aviation passenger transport competition and collaboration[D]. Dalian Maritime UniVersity, 2012.

[3]. Statistical Bureau of the people's Republic of China. China statistical yearbook-2014[EB/OL], China statistical yearbook-2013[EB/OL], China statistical yearbook-2012[EB/OL].

[4]. Le Feng. Research on the capacity of the economic population in Beijing City[D]. Capital UniVersity of Economics and Business, 2009.

[5]. Bayen, AlexandreM., Grieder, Pascal, et al. A control theoretic predictiVe model for sector-based air traffic flow. American institute of Aeronautics and Astronautics inc,2002.

[6]. Chen, Bor-Sen, Peng, Sen-Chueh, et al. Traffic modeling, prediction, and congestion control for high-speed networks: A fuzzy AR approach. iEEE, 2000. 